\title{
LA METAFÍSICA DEL HUACHO. Visita A LA OBRA MADRES Y huachos. Alegoría del mestizaje chileno De Sonia MONTECINO*
}

\section{Miguel Alvarado Borgoño ${ }^{1}$}

\section{Resumen}

Este artículo cumple dos objetivos relacionados con obra de la escritora y etnóloga chilena Sonia Montecino Aguirre titulada Madres y huachos. Alegoría del mestizaje chileno: el primero es presentar la problemática del género femenino en el contexto latinoamericano, desde la condición de bastardía o huacherío como fundamento, tanto en lo que respecta a la madre que asume solitaria su rol como tanto en las de los hijos e hijas que crecen en una situación de "bastardía esencial". En segundo lugar, dar cuenta del surgimiento de la Antropología Literaria Chilena como escritura de cruce entre la literatura y la ciencia etnológica.

Palabras clave: Orfandad, Latinoamérica, antropología literaria, género femenino.

\section{Huacho Metaphysics. Visit the BOOK MOthers and HUACHOS. ALLEGORY OF THE CHILEAN MISCEGENATION OF SONIA MONTECINO}

\begin{abstract}
This paper has two objectives, from reading the work of Chilean writer and ethnologist Sonia Montecino Aguirre entitled "Mothers and outcasts. Chilean mixing allegory "; the first is to present the problems of the female gender in the Latin American context, since the condition of illegitimacy or huacherío as a basis, this both in regard to the lonely mother who takes his role, as well as those of the children who grow up in a situation of "essential illegitimacy". Secondly account for the emergence of anthropology as Chilean Literary writing cross between literature and ethnology.

Keywords: Orphan, Latin America, literary anthropology, female.
\end{abstract}

* Este artículo fue elaborado en Alemania en el contexto de la ejecución del proyecto financiado por el Deutscher Akademischer Austauschdienst (DAAD): "Racism and xenophobia in the basis of a vision of national identity in South América". Siendo el autor profesor visitante de la Universidad de Frankfurt del Meno en su Instituto de Filología Románica.

1 Chileno, Doctor Ciencias Humnas. Filólogo y etnólogo. Profesor Visitante, Johann Wolfgang GoetheUniversität Frankfurt am Main, Deutschland. Profesor Titular, Instituto de Filosofía, Universidad de Valparaíso, Chile. Miembro del Claustro del Doctorado en Estudios Interdisciplinarios y del PMI en esta misma universidad chilena.miguel.alvarado@uv.cl 


\section{Introducción: el padre como ausencia visto desde el experimento textual}

En Chile han aparecido, desde hace treinta años, una serie de textos de "frontera" que han sido definidos en libros, tesis doctorales y artículos científicos como Antropología Poético Literaria Chilena por parte de investigadores chilenos tales como Iván Carrasco, Miguel Alvarado y Pilar Valenzuela. Se tratan de textos híbridos que se encuentran tipológica y estilísticamente ubicados entre la literatura y la ciencia etnológica, y en donde sus autores son, por lo general, antropólogos de profesión quienes ofician como escritores, algunos con un nivel nacional o internacional de reconocimiento (Clemente Riedemann, Andrés Recasens, Ivonne Valenzuela, Sonia Montecino, entre otros y otras).

En este artículo deseamos dar a conocer esta Antropología Poético Literaria, pero desde la especificidad del género femenino, como problemática analítica y del mismo modo identidad textual, de un texto fundamental de esta corriente, el cual da cuenta y a la vez genera nuevas subjetividades; para ello nos centraremos en el libro Madres y huachos. Alegoría del mestizaje chileno, obra de la Premio Nacional de Humanidades y Ciencias Sociales de Chile (en el año 2013), la conocida la etnóloga y novelista Sonia Montecino Aguirre (1954). En este libro de ensayos literarios y antropológicos, Montecino reflexiona sobre la condición esencial de "hijo sin padre conocido", condición que es propia de la mayoría de los latinoamericanos desde la conquista europea, lo que posee una continuidad en el siglo XX en la figura del "huacho", que derivado de la voz quechua Huaqcha (niño huérfano que es protegido por el Incanato) pasa a ser un adjetivo descalificador, sinónimo de bastardo. Por tanto, la autora sostiene la existencia de una suerte de "bastardía esencial" de los latinoamericanos en estos quinientos años de aculturación eurocentrada, la que, por contigüidad, también se extiende a los chilenos.

Nos centraremos concretamente en el influjo que ha tenido en el medio chileno y latinoamericano esta "bastardía esencial", lo que se ha expresado en las reediciones, premios, críticas laudatorias y citas que este libro ha merecido; pero más concretamente, nos centraremos en la subjetividad que involucra este proyecto literario y etnológico, que da cuenta cómo lo femenino se constituye desde una ausencia de 
lo masculino, ausencia como pareja de "la" mujer y del mismo modo abandono del padre, y por ello se erige desde una falta, lo cual contradice la idea "lacaniana" del padre como epicentro de la cultura y de la ley. Por tanto, ¿portaríamos los latinoamericanos una cultura descentrada por la ausencia del padre como eje de integración psicocultural? Requeriremos ubicar las formas literarias que a su vez van generando una subjetividad en la cual la figura del padre como "falo totémico" es textualmente sustituida por otros tótems generadores de integración, pero desde figuras no específicamente patriarcales, al menos en la idea eurocentrada del patriarcado.

\subsection{Atributo apócrifo del padre: ausencias y elocuencias de los sometimientos}

La noción de géneros nómades (ver. Judith Butler, 2001, 2002, 2004, 2006) nos remite a algo profundamente nuevo y, del mismo modo, algo profundamente antiguo en Latinoamérica nos traslada a la interrogante por los roles y a la definición misma de lasidentidades genéricas mutantes, desde una identidad sociocultural diversa, heterogénea y especialmente en rotación en Latinoamérica de los últimos quinientos años, que debe adaptarse a las formaciones sociales, desde el mercantilismo colonial hasta el capitalismo periférico. Ello desde la centralidad socioeconómica la hacienda servidora de la metrópoli, hasta la pauperización de los "desterrados de la modernización", que habitan las periferias (la mayoría de los latinoamericanos y latinoamericanas), ello en el escenario del capitalismo sudamericano, que quizás más que nunca es hoy en el siglo XXI posee una condición estructural adyacente y dependiente.

En Latinoamérica, los roles genéricos se reordenan, modifican y reelaboran desde el momento de la conquista ocurrida desde el siglo XV. Se trata de un "temblor cósmico" que da vuelta todos los sentidos y los significados para los indígenas latinoamericanos. Este "temblor de cielo" se vive como un rito por la supuesta "visitación de dioses" y por la tragedia también ritual de la muerte, ello concretado en el asesinato, la explotación en el trabajo y el contagio de enfermedades que padecieron los habitantes originarios. Esto forma parte de un gran un acto de violencia y, particularmente, de violencia ritual, un rito unido a la palabra que justifica el genocidio y le da sentido cósmico, que obliga a repensarse y a originar un nuevo mundo, donde la nueva mujer no es ni la indígena 
nativa ni la europea trasplantada. Es una ausencia identitaria específica, pero una presencia física, con una prominente presencia funcional y simbólica en la organización de la producción y de las subjetividades en este nuevo mundo.

El descubrimiento de América y posterior colonización es el genocidio más importante del que se tiene registro en la historia humana, y desde él se generó una identidad mestiza e imprecisa que no dio lugar, como lo pretendía el terreno de la ilusión romántica en la fundación de los Estados Nacionales latinoamericanos, a una "nueva Europa", y, en muchos sentidos, Latinoamérica vive unos sincretismos aún inconclusos. Todo tuvo que ser resignificado y sigue aun siéndolo, en una dialéctica entre la identidad imprecisa mestiza y la cultura eurocentrada, pero generando a sus actores y sus signos, casi sin proponérselo, con trazos particulares y genuinos, especialmente por parte de las formas culturales populares.

Para hablar de lo femenino, fue necesaria otra escritura, otras palabras y otros valores, ello desde la rotación de los signos, donde la escritura de género se invisibiliza (de partida porque no se enseñó por varios siglos a leer a las mujeres y luego porque no se reconoció su escritura más que por textos marginales como las confesiones de monjas enclaustradas, la poesía de circulación doméstica o en salones oligárquicos, y las cartas íntimas. Esta ausencia de la voz escritural femenina ha definido a un tipo textual desde la primera mitad del siglo XX, donde aparecen literaturas de mujeres con una identidad genérica femenina, $y$, como novedad y desafío, aparece en el extremo del continente un género híbrido que comienza hoy a pensar la identidad femenina desde su potencia como maternidad biológica y cultural (no naturalizándola sino resaltando su eficiencia simbólica). Se trata de La Antropología Literaria Chilena, y específicamente desde Madres y huachos. Alegoría del mestizaje chileno de Sonia Montecino, que apunta a esta "falta del falo totémico" que define la ley eurocentrada.

Es justamente una ausencia, la cual intenta ser sustituida por un juego de máscaras, donde muchas veces es la mujer latinoamericana la que defiende los valores que más la perjudican, y ello justamente para subsanar esta falta: es por ello que aquí hablaremos de la identidad femenina, desde el ejercicio del falocentrismo, pero siempre desde su ausencia, desde su falta y desde los intentos de sustitución, reemplazo y soldadura de la rotura en la "cadena significante". 
Afirmamos también que, simultáneamente, esta palabra ha surgido desde un género híbrido y por parte de mujeres, en este caso de Sonia Montecino, que nos invita a la reflexión. La hipótesis de la escritora y antropóloga chilena en su ensayo antropológico literario Madres y huachos. Alegoría del mestizaje chileno, consiste en que la condición de orfandad es la que define a Chile y, por extensión, a lo latinoamericano en el plano del género femenino, sino también en el que superando esta orfandad la especificidad de género femenino, respecto del modo en que se desenvuelve la síntesis barroca desde la conquista para todos y todas en un potente "aquí".

Pero queda una pregunta abierta: si no existe el varón como eje de la integración, ¿cómo se integra el sistema étnico social latinoamericano? Se trata para nosotros de un "barroquismo del padre ausente", que en su ausencia constituye una falta y desde una falta origina máscaras y por lo tanto una capciosa identidad. Sonia Montecino es el detonante de una reflexión sudaka ${ }^{2}$ y, de algún modo, marginal y contestataria del orden burgués, que intentamos continuar, aunque nunca sobreinterpretar. el libro de Montecino es en sí una generosa invitación, ya que la proyección que damos a sus ideas es nuestra responsabilidad porque son nuestras opiniones, una forma asumida de "delirio", como creación y jugada.

\subsection{El padre, eternamente el signo, el ancla y el encadenamiento}

Cuando el psicoanalista Jacques Lacan suspende su propia Escuela, cometiendo casi un parricidio voluntario, anuncia su cometido desde su condición de gran padre perverso y polimorfo, y así consciente y cruel; da cuenta icónicamente del papel del padre en la cultura occidental como sostén simbólico de la ley, pilar del sentido, epicentro de la estabilidad y la integración del sistema social. Lacan, el inanalizable según Roudinesco (vid. 1993), es el que "no tuvo padre" en un sentido conceptual, cometiendo la originalidad de mezclar más allá de lo que se creía posible distintas disciplinas y teorías, incluso teniendo que refundar el freudismo para crearse a sí mismo. Por ello, es el único padre posible capaz de asesinar

2 Sudaka es un término que ya se encuentra inserto en el Diccionario de la Real Academia Española de la Lengua, pero no debemos engañarnos, sin dudad es despectivo; su uso masivo para algunos comienza con la llegada de exiliados latinoamericanos a España en los 70 y 80 y la llamada "movida sudaka". En este artículo queremos resignificarlo y darle contenido y dignidad. 
ritualmente su propia escuela, dejando en la orfandad incluso a aquellos que aseguran ser "más lacanianos que Lacan".

Desde un intento de reflexionar lo latinoamericano, en las distintas formas de pensamiento situado que ensayamos, nos preguntamos ¿Qué ocurre cuando esta figura totémica está ausente? ¿Cuándo el padre es una ausencia que no del todo suscita añoranza?, y peor aún ¿Qué ocurre con un sistema cultural cuando se define desde esta condición de orfandad? Tanto o más que el padre violento, el padre como huella aislada, como ausencia, es aún más dañino. Esta privación de presencia ocasiona el desmembramiento de la personalidad, generando sufrimiento intrapsíquico. En esta situación, la presencia vive en el plano de la subconsciencia pero no se materializa en el gesto del abrazo: el padre que ignora es más cruel que el padre que conscientemente daña. El daño de ignorar es negar mezquinamente un trozo de vida, una parte de la estructura psíquica diseñada para soportar temporales, remedio para el desamor o para el exceso de éste y, en general, para todas las formas de dolor, ¿será tal nuestro dolor? ¿Cómo recompusimos los bordes de esa rasgadura?

\section{Montecino piensa situadamente para invitar a seguir pensando}

El libro de Sonia Montecino se estructura desde esa carencia que, de dolorosa, pasa a ser ritual y luego festiva. La autora demuestra que la ausencia del padre no es una carencia, sino una ausencia legitimada, una forma de hacer cultura (como en el sistema avuncular polinésico), particularmente donde la figura del padre la ocupa el hermano de la madre.

El sistema cultural latinoamericano resuelve en el rito una vivencia que llega a no ser carencia y, por ello, no llega a ser dolor sino diferencia y especificidad. Tal ejercicio teórico requiere de la transgresión textual para hacernos olvidar el pecado de negar al padre, de negarlo más de tres veces sin dejar que ningún gallo cante. Tal pecado sólo puede hacerse desde un texto heterodoxo, desarraigado de los géneros y, por ello, luminoso en su libertad expresiva: el breve libro de Montecino.

Este texto de Sonia Montecino es, sin duda, un nicho de transgresiones, y toda lectura interpretativa del mismo debe llegar en algún momento a 
la enumeración de las irreverencias ideológicas de género, la científica, y por sobre todo, la más importante para este estudio, la transgresión tipológica: gozosa es la transgresión a la cual nos convida Sonia Montecino con este libro: travesía en nuestras máscaras, por nuestros ladinos disfraces de mestizos, según la pensadora Guadalupe Santa $\mathrm{Cruz}^{3}$, prologuista del libro (ver. Montecino 1991). En este texto, que viola públicamente una de las leyes primordiales de nuestra cultura, la palabra (como encubridora de la experiencia y el rito que le están disociados), nos provoca en forma ininterrumpida un gesto de asombro, de temor incluso, ante las figuras reconocibles que éste desentraña. Sorpresa y euforia contenida de quien es atrapado en su propia bufonada, es un "demonio feliz" sin lugar a dudas, descubierto en la comedia festiva que ayuda a levantar como escenario" (ver. Montecino 1991).

En este análisis intentamos demostrar cómo estas rupturas se generan desde un argumento, el de la existencia de una identidad cultural barroca, basándose en una apertura a la intertextualidad científica y literaria, y desde una identidad de género: la de "ser mujer que escribe", hasta llegar a un tipo de texto que definimos como barroco, tanto porque habla del barroquismo latinoamericano, como porque sus formas textuales, recargadas de un "barroquismo textual", lo asocian con la literatura, y en el que la metáfora, bella y estridente, ocupa el lugar que en algún momento ocupó el dato empírico". El libro de Montecino hace pensar -y nos hace a nosotros y nosotras en Chile pensarnos aquí-, justamente porque su primera ruptura es con la etnografía como método de campo para transformarse en propuesta de una "etnografía de las subjetividades" expresadas en textos orales y escritos a los que permanentemente se alude.

Desde el subtítulo del libro, como primera estrategia paratextual, se habla justamente de una "alegoría del mestizaje chileno". Sabemos

3 Nacida en Nueva Jersey, Estados Unidos, cursó estudios de Filosofía en la Universidad Católica de Chile, pero tuvo que partir al exilio después del golpe militar de 1973. En Bélgica estudió grabado en la Academia de Bellas Artes de Lieja y se licenció en Formación de Adultos y Educación Permanente en la Universidad de la misma ciudad. Formó parte de la Asociación de grabadores La Poupée d’Encre hasta su retorno a Chile, en 1985. Autora de ensayos, novelas y textos donde combina la escritura y el grabado, publicó su primera novela, en 1989: Salir, en editorial Cuarto Propio. Le siguen Cita Capital (1992) y El contagio (1997) en la misma editorial. En 2001 editó Los Conversos y en 2005 Plasma, ambas en editorial LOM; en 2006, La cordillera en andas, donde incluye versos y grabados, editada por Francisco Zegers y en 2011 Ojo líquido (Palinodia) y Lo que vibra por las superficies (2013, Sangría Editora), una selección de ensayos escritos a lo largo de años. Murió el 25 de enero del año 2015. 
que una alegoría no es de ninguna manera una descripción objetiva; por el contrario, es una recreación creativa, un hecho semiótico que mantiene el vínculo entre significado y significante de forma mimética, no pudiendo nunca confundirse lo alegorizado con la alegoría misma como significante. El texto de Montecino no es Chile en ninguna de sus esferas, y ninguno de los valores que nos propone tiene pies ni tampoco camina. Este libro es un mundo propio que se gesta en la conjunción de las condicionantes de la autora empírica, combinadas creativamente por la autora textual, y de allí la "barroca alegoría", que es el fundamento del propio delirio suscitado por las obsesiones de Montecino.

El libro está compuesto por textos disímiles, lo cual se explica desde el origen de los mismos; no obstante, los hilos conductores son básicamente temáticos o semántico- macroestructurales (ver. Van Dijk 1989), se definen desde temas: la mujer y la maternidad, la orfandad expresada en el "huacherío", la síntesis ritual, la oralidad, el poder. Su presunción esencial es la primacía que tendría la condición de hijo ilegítimo o huacho en la identidad cultural de Chile y, por extensión de Latinoamérica. Lo anterior se apoya, en términos argumentales, en fuentes sociológicas, antropológicas e históricas, y recurre, a nivel del estilo (en el plano de las metáforas utilizadas y de las citas que afianzan la textualidad), a las formalidades de la literatura, la que como retórica literatosa se constituye en una fuente básica. Por ello, lo literario es tanto un sostén intertextual como expresivo.

El texto ha sido leído como un alegato desde el género sexual. Nosotros creemos que, sin dejar de serlo, es ante todo un experimento textual que busca llenar vacíos, que no sólo se remiten al tema del género sexual, sino que guardan relación con la expresión misma en un contexto de redemocratización chilena. Justamente si Chile salía de una dictadura machista y criminal, el pensar el género involucraba pensar el proyecto cultural de la redemocratización chilena. Por ello, además de que demuestra un argumento respecto de lo femenino (lo que en sí hace), este texto es un experimento que abre la ruta a nuevas formas expresivas: así la problemática de género desborda lo femenino e inunda a la pregunta por la sociedad sudaka toda. 


\subsection{Escribir desde el género femenino, cuando todo comienza}

Este libro fue escrito en parte en dictadura y publicado en democracia, pero en un contexto donde la antropología chilena era un gesto exótico, mínimo y poco peligroso, una disciplina de elite que era pasada por alto por los mecanismos de la represión en la academia. Por este motivo impacta más al campo literario que al científico. Desde la concesión del Premio Academia Chilena de la Lengua en 1992, ya la autora había publicado una novela con bastante éxito de crítica (La revuelta, en 1988). Madres y huachos. Alegoría del mestizaje chileno, es el primer texto donde verdaderamente se ve la audacia de la teoría experimental dentro de la antropología chilena contemporánea.

Para ello, este libro de Montecino debe romper con una premisa básica que la antropología chilena aprendió de sus maestros europeos. Se suponía que la reflexión antropológica teórica sería fruto esforzado de años interminables de trabajo de campo; así entendido, el esfuerzo teórico de la antropología en su función de "acumuladora de verdades", es posterior a un proceso sistemático de búsqueda de información empírica. La data es posible de encontrar a través de la experiencia de nuestros sentidos, los que no mienten, desde el principio positivista y neopositivista de isomorfía entre lenguaje, pensamiento y realidad. Por este motivo, el texto de Montecino se sale del margen. Visto así, este libro es antropología, pero no la antropología (insistimos) que enseñaron los maestros extranjeros, (Alfred Metraux, Mischa Titiev, Milan Stuchlik, entre otros) y que sus discípulos latinoamericanos digirieron con sumisión, en ocasiones con inteligencia y, por sobre todo siempre con disciplinamiento y disciplina, siguiendo una forma logo centrada de hacer ciencia de la alteridad.

\subsection{Género y metatextualidad: ensayar algo más que el ensayo}

Desde una mirada tipológica poco profunda, el texto de Montecino es un ensayo. Así nos lo dice su autora y así es leído; no obstante, cabe inmediatamente la pregunta ¿De qué tipo de ensayo se trata?, ¿Es un ensayo antropológico, un ensayo literario, un ensayo histórico o un ensayo sociológico? Nuestra hipótesis sostiene que se trata de un ensayo antropológico literario, y ello se demuestra en una visión de conjunto 
del mismo. Las preguntas anteriores no son solamente importantes para nosotros en este artículo. Ya se lo plantea la propia autora en el inicio del libro y la respuesta la intenta dar ella misma desde el principio. Pero, a decir verdad, no nos deja del todo satisfechos: "se trata de un ensayo es decir de una tradición escritural, que más que en la rigurosidad se posa en la libertad de asociar ideas sobre un objeto" (ver Montecino ). Luego agrega justamente el dato respecto de su valoración de lo intertextual, lo cual nos da luces para entender su esencia tipológica, "escritura que se vale de otras, escritura que toma lenguajes y metáforas para constituirse" (ver Montecino 1991).

Queda pues la pregunta por la tradición que da sentido al texto en términos de género y la continuidad que intenta forjar. Para nosotros, ello se explica por el carácter transgresor de la obra. Se trata, en definitiva, de un nuevo tipo de ensayo literario y del mismo modo de un texto con raíces científicas, que se abre desde la intertextualidad y la metalengua (ver. Mignolo 1986) a un nuevo tipo de género textual.

En lo que respecta al plano concreto de la metalengua de este texto, es difícil hablar de un texto que ya ha tomado un carácter "canónico" en el ambiente intelectual chileno. No obstante, la transgresión que significa este libro aún en el canon antropológico tradicional para Chile y Sudamérica, al incluir tanta referencia literaria y (por sobre todo) al no significar en sí mismo una sistematización de una experiencia de campo prolongada, representa así una nueva forma de hacer antropología y también de hacer literatura.

La utilización del lenguaje, que proviene del ámbito del arte y la literatura, no es nueva en las ciencias sociales latinoamericanas. Se trata justamente de retomar una línea que proviene del romanticismo sudamericano, desde Sarmiento a Martí, que representa la base primero del ensayismo, y luego del propio texto con pretensiones científicas sociales. Mas, la novedad del libro de Montecino es el abierto recurso a la analogía estética como modo de articular el texto y darle un sentido; dice todo cuidando el estilo, pero además el argumento racional se define desde categorías originadas en lo estético, particularmente en lo estético literario.

El eje metalingüístico se define de la siguiente forma: el Proyecto Ecuménico del Barroco determina, desde el primado del rito y de la 
oralidad, la aparición de una identidad mestiza la que se juega en las binariedades hombre/ mujer, blanco/ negro, y dialécticamente se resuelve en la polaridad esencial de nuestra identidad como país, la de la madre y su(s) huacho(s).

Concretamente en la metalengua de este texto, vemos diversas intencionalidades en su émica: una es ideológica, -la del género sexual-, y la otra es teórica; no obstante, para nosotros, la teórica rebasa y supera ampliamente a la ideológica. Si se trata de un texto de agitación, ello se hace desde una originalidad teórica que sobrepasa la meta valórica. Pero existe un tercer factor metalingüístico implícito y que es la licencia de la metáfora, la posibilidad implícita de recurrir a la metaforización de los conceptos para elaborar el texto. Justamente, este factor de la metalengua, el cual aunque se encuentra centrado en la reflexión analítica, no obstante, recurre a un lenguaje lleno de belleza barroca que da forma al tipo textual; ello no constituye argumento sino una práctica textual permanente que representa un hecho fundante también de la émica del libro.

Respecto del pensamiento de Sonia Montecino, y específicamente respecto de la metalengua del libro aquí analizado, existe un alegato externo que resulta fundamental. Se trata del discurso de aceptación del Premio Academia Chilena de la Lengua, donde la metalengua a nivel teórico e ideológico queda bastante clara:

la oralidad es la forma en que el ethos latinoamericano ha transmitido su historia y su resistencia frente a la expansión del texto. La oralidad es también el lenguaje, que apropiado por las mujeres, desencadena un habla que se resiste a una cierta economía porque sus tiempos nos son los de la producción en serie sino los tiempos artesanales de la elaboración de alimentos, del hilado, del arrullo maternal, de la dilapidación festiva (...) claves de comprensión en donde tradición oral y tradición escrita, se ha roto y palabra se han conjuntado para proponer una escritura de bordes, de sitios fronterizos. (Discurso entrega... 3)

Como ya afirmamos, en el plano de la doctrina, estos textos se definen metalingüísticamente desde la opción de género El género, y no otra cosa, es el punto articulatorio de las orientaciones de valor presentes; más aún, en el plano pragmático el texto tiene un intención ideológica: la de pensar 
el tema de la identidad cultural chilena desde lo femenino, y así lo lograr, al menos en lo que respecta a la presentación de un esquema coherente consigo mismo. Esta Teoría del Huacherío conlleva asumir un desarraigo fundamental, que pone en la madre, es decir, en lo femenino, el acento, y allí encuentra su fuente explicativa; no obstante, es una metalengua plenamente situada, comprometida con su contexto social inmediato y mediato; es parte del esfuerzo de una intelectualidad que responde al proyecto refundacional de la dictadura militar, pero es también un pensamiento definido desde el género femenino. Por ello, no sólo es antropología o literatura: es también ideología. En este sentido, vemos una metalengua militante, una sofisticada escritura para la agitación.

\section{Agitar violentando el secreto profesional}

En lo que respecta a las bases de la metalengua, reconocemos dos fuentes metalingüísticas fundamentales en este libro, las que se nos presentan básicamente como fuentes teóricas; ellas están fundadas en el aporte de dos importantes pensadores chilenos: Jorge Guzmán (1984, 19931) desde el ámbito de la teoría y crítica literaria, y Pedro Morandé (1984) desde el ámbito de la teoría sociológica. Ni siquiera las fuentes antropológicas o las teóricas del género tienen una influencia tan decisiva en la metalengua auto justificante de este libro, en la émica implícita y explícita del texto. Guzmán aporta básicamente un elemento en la metalengua que se fundamenta en la pregunta por el mestizaje. Su argumentación respecto de la oposición sociocultural entre lo blanco y lo negro que debe, para Guzmán teñir, tanto la escritura como la lectura de textos, resulta un factor primordial. En Montecino es patente a nivel de su metalengua, su voluntad de escribir desde lo mestizo, pero del mismo modo invitar a leer desde allí, con ello lo mestizo clave asumido como clave hermenéutica y creativa, se constituye en una dimensión émica fundamental. Así como Guzmán hace, por ejemplo, una lectura mestiza de Vallejo, Montecino propone una lectura mestiza de nuestra identidad. Con ello, la clave ideológica del género se ve complementada con este nuevo elemento émico, esto es la voluntad de leer y, por tanto, escribir desde la mezcla.

Otro aspecto de su émica es el fundamento que existe en Morandé, desde una perspectiva teórica. Podríamos hacer un largo ensayo respecto 
del aporte de este autor a toda la obra de Montecino; no obstante, si nuestra interrogante es tipológica, y particularmente en este nivel, metalingüística, debemos afirmar que el tema del proyecto ecuménico del barroco es un aspecto esencial, no solamente a nivel teórico, sino como argumento justificante que da sentido a la exposición. Si Guzmán invita a pensar a leer y a escribir a Montecino desde lo mestizo, Morandé le dice cómo se produce este mestizaje desde su teoría del sincretismo generado desde este proyecto ecuménico originado en el siglo XVI.

Volviendo a Guzmán, la influencia reconocida de este autor en la metalengua se define para nosotros en una invitación a la transgresión. Guzmán abre la pauta y el texto de Montecino entra de manera violenta y bulliciosa. Si nuestra mirada es un tanto superficial, el texto de Guzmán apenas intenta proponer un nuevo camino para la crítica literaria. Según Guzmán, la importación ingenua y crítica de métodos de análisis literarios producidos en otras culturas, determina siempre "un efecto ocultante de la propia realidad cultural" (Contra el secreto profesional 13).

Esta desnaturalización del método sistemático de lectura es combatida por Guzmán desde procedimientos semióticos culturalmente situados. Desde categorías como hombre / mujer y por sobre todo blanco/ negro, Guzmán logra reconocer la poesía de Vallejo, asumiendo lo que Bajtín entiende como una "pluralidad de voces" que intercalan dentro del marco de su propia coherencia la cual es originada en su contexto cultural e histórico. Montecino retoma esta polaridad blanco/ negro y hombre/ mujer, como una clave hermenéutica: "Los análisis sobre la mujer en nuestro territorio podrían ser aún más fecundos si profundizáramos en el espacio de los símbolos que rodean su constitución como sujeto (...) En este sentido el ícono mariano muestra, por ahora, sólo el vértice de un iceberg que flota en la superficie del cuerpo social mestizo" (Madres y huachos 33).

El aporte de Guzmán es inmenso en la elaboración no solamente de una hermenéutica en el plano metodológico, sino en la invitación transdisciplinaria, lo cual abarca la posibilidad de leer desde polaridades bajo la forma de pares binarios que decanta en la polaridad madre y huachos, factor fundamental del texto; Jorge Guzmán, aporta el enfoque desde la madre, el otro polo de nuestra construcción social de las diferencias genéricas (Madres y huachos 55). 
Más aún, la invitación de Guzmán no es solamente la invitación a un método, sino por sobre todo es la apertura a un nuevo modo de transdiciplina; la metalengua del texto lo afirma a cada momento. Sería admisible la inclusión de sociólogos como Pedro Morandé en su discurso; no obstante, al introducir el pensamiento de Jorge Guzmán, rompe los límites, transgrede alevosamente lo que es la formalidad del texto antropológico chileno. Se permite extraer no sólo una referencia anecdótica para la elaboración de su discurso, utilizando a un humanista que como especialista es más bien ajeno a las ciencias sociales, y lo ubica en el epicentro de su argumentación. Con ello, la transgresión se completa, y la metalengua da lugar a un texto que no es el antropológico chileno de la década de los ochenta del pasado siglo sino que es otra cosa: un híbrido expresivo y textual.

Para nosotros, la inclusión de Guzmán abre la puerta para la constitución de un nuevo tipo textual, el cual desde la voz antropológica se sumerge en la transdisciplina y sigue un camino propio en el cual la fidelidad a la semántica de la antropología deja de importar. Lo que importa ya no es hacer o no texto antropológico, sino contar lo que se quiere y hacerlo como se quiere, para demostrar el argumento en una lógica que une la recargada belleza de la expresión con la demostración del mismo. Montecino termina haciendo aquí Literatura con mayúscula, que no deja de ser ciencia experimental y reflexión política, todo esto logrado de manera simultánea y creativa.

\section{El barroco como base de la metatextualidad}

Hemos situado al concepto de barroco como un factor determinante, no solamente porque corresponda a las categorías conceptuales de Pedro Morandé (1984), sino porque desde esta perspectiva abre el camino para la innovación textual en Montecino, como si se dijese que si América Latina es barroca entonces barroco es este texto que creemos, situado en este suelo y, por ello, definido desde este barroquismo esencial.

El concepto de "Barroco Latinoamericano" es de antigua data en nuestro continente respecto de su uso por parte de nuestra intelectualidad. Está presente en la obra de Alejo Carpentier y Pedro Morandé (de una punta a la otra del siglo, y desde el arte hacia las ciencias sociales), y aún antes que ellos desde conceptos como los "de barroco popular americano", fundamentales en la obra y metalengua del poeta chileno 
Pablo de Rokha4. Por ello, la inclusión metalingüística del concepto de barroco en este texto supera lo teórico para constituirse en el elemento esencial de la metalengua.

Si el tema fundamental abordado consiste en lo femenino en la identidad mestiza, en el barroco sale hasta por los poros, barroco en una lectura histórica, barroco en una lectura sociológica, y, por qué no decirlo, asumiendo una retórica barroca al momento de realizar la escritura, con una belleza dentro de la cual no deja indiferente lo recargado del estilo, la vehemencia se ve apuntalada por un modo de escritura pesado, como puede ser pesado todo texto donde la belleza se comprime, y que el lector descomprime, para llegar a inundarlo en su lectura desde las primeras páginas. Desde nuestra lectura del libro de Montecino, podemos decir que el concepto de barroco es una categoría de doble registro, ya que se presenta desde un doble origen en la estética literaria y en las ciencias sociales latinoamericanas. Su aparición en la cultura latinoamericana es anterior en la literatura y su metalengua que en la teoría social; no obstante, para poder llegar a constituirse una teoría sociológica del barroco americano, como la de Morandé, tiene antes que existir una metalengua literaria como la de Alejo Carpentier o Pablo de Rokha.

Esta metalengua literaria, nos da algunas pistas para responder a la pregunta ya planteada por el itinerario del concepto de barroco, mostrándonos de manera prototípica cómo la noción de barroco inunda la escritura, desde la literatura hasta las formas escritúrales más recónditas, siendo Madres y huachos. Alegoría del mestizaje chileno una expresión axial de ello. Las mismas sorpresas vividas por Carpentier son las del etnólogo en un contexto donde lo que la literatura antropológica clásica describe como la "alteridad radical", es decir la "absoluta diferencia respecto de lo occidental" y la literatura surrealista definida como la escritura de lo inconsciente, se transforma en realidad nítida e identificable en la propia biografía y en la vivencia de la experiencia colectiva. Respondamos a la pregunta por el barroquismo de la escritura

4 Pablo de Rokha, cuyo nombre real era Carlos Díaz Loyola (Licantén, Región del Maule, 21 de marzo de 1894 -Santiago, Región Metropolitana de Santiago, 10 de septiembre de 1968), obtuvo el Premio Nacional de Literatura de su país en 1965 y es considerado uno de los cuatro grandes de la poesía chilena junto con Gabriela Mistral, Pablo Neruda y Vicente Huidobro. También es considerado un poeta vanguardista y de gran influencia en la lírica en Chile y en la poesía beat norteamericana, por ej. Allen Ginsberg . 
de Montecino con otra pregunta: ¿Por qué el contexto histórico cultural que determina el surgimiento del realismo mágico no podría determinar un tipo de escritura antropológica? Sobre todo si ésta se abre a una visión que entiende la identidad latinoamericana como barroca y que asume sin tapujos la posibilidad de la influencia de la teoría literaria a nivel del argumento, y de la intertextualidad en los planos de la narración y la explicación.

Por otra parte, si entendemos por racionalidad, según el uso que Morandé (1984) hace de las categorías webereanas, como el conjunto de valores que definen "acción social en un contexto específico", entonces este concepto puede ser extrapolado más allá de los límites de la modernidad y del mundo occidental hacia el universo axiológico que delimita e induce la conducta del hombre precolombino latinoamericano. Por esto debemos decir que esta racionalidad se mueve dentro de los límites de las sociedades arcaicas y, por lo tanto, lo substancial de ésta es el ámbito de lo dramático sacrificial.

El drama como exacerbación de la expresión de los significados y el sacrificio como inmolación socialmente compartida, como ofrenda dentro de la estructura social, dan para Morandé como resultado una cultura en la cual el dolor da sentido a lo social y el quiebre continuo no es más que un eslabón dentro de una continuidad de hechos de carácter dialéctico, en la cual desde la persistente hecatombe surge el replanteamiento, al que dentro de nuestra racionalidad damos el nombre de "porvenir", queda la pregunta ¿Cómo se vive entonces el par binario sacrificio/género?

Esta lectura de la temporalidad se funde, para Montecino, en aquello que por nuestra parte denominamos "el tiempo de lo femenino", tiempo en el que las labores diarias y los procesos biológicos se ven aunados en una temporalidad, que se expresa por la oralidad y que se diferencia radicalmente de la cronología de la producción capitalista. Desde las citas a Tamara Kamenszain, Montecino hace una fecunda síntesis con el pensamiento de Morandé, para explicar en un lenguaje lleno de bellas metáforas, el modo en que el tiempo pasa a leerse de manera distinta y, por ello, genera un orden social sumergido, que opera realmente, pero bajo la forma de mecanismos poderosos e invisibles. 
Por otra parte, Montecino afirma desde Morandé la injerencia de lo cosmocéntrico en la identidad latinoamericana, es decir, tiene una concepción del cosmos en la cual el centro es la propia cultura, particularmente en el caso de las altas culturas como los Incas, Mayas y Aztecas, siendo también el centro del universo. Esta faceta, propia de las culturas precolombinas determina la existencia de una realidad mental específica, la cual podía traducirse, por ejemplo, en un tipo de religión puntual, y tiene que ver con fenómenos como la estructura social, o con modos particulares de vincularse con la naturaleza en el plano ecológicocultural.

El cosmocentrismo define un vínculo con la organización social y con la relación tecno-ambiental, y ese vínculo se da fundamentalmente en el plano de los valores, quedando esto expresado en la presencia del sacrificio en todas las esferas de la vida de estas sociedades, desde lo mítico hasta lo material, lo cual se proyectaría en nuestra sociedad latinoamericana en la actualidad. Para el esquema de Morandé, esta contraposición entre lo europeo y las culturas precolombinas, más que significar una ruptura o un quiebre, en el sentido de apocalipsis absoluto, más bien representa un encuentro de carácter dialógico, en tanto significa que por parte del español y por parte del indígena precolombino tuvo que existir un pensarse mutuamente, lo que conlleva la necesidad de idear categorías que permitan, dentro de los límites de la propia cultura, dar cuenta de este otro cultural tan extraño y, al mismo, tiempo tan presente.

En Montecino, la mujer es la "radicalmente diferente". Su diferencia, al ser genérica e involucrar aspectos biológicos y psicoculturales, determina un segundo nivel de alteridad. Ello pone a la mujer en un papel nuevo y distintivo en el que, desde lo doméstico, subordina, aunque también provee de otros mecanismos. El papel de la mujer, y también sus ejes de poder, se define desde la conquista misma. Para Montecino es la madre violada, la distinta que por la consumación sexual (por puro efecto de la pulsión más rotunda) llega a convertirse en la compañera y en la compañía; no obstante, la asiste la invisibilidad y el poder de estar en todo lo habitual, en la cotidianeidad, y como sumatoria de las partes lo cotidiano es el todo más significativo de la existencia. 


\section{La intertextualidad para la belleza en la cavilación}

La propia autora nos confiesa su mododeentenderelensayo.Segúnella, es una escritura que se vale de otras escrituras. Entonces, evidentemente, el nivel intertextual pasa a tener un papel preponderante al momento de definir la identidad del texto. Este proceso de intertextualización responde, por una parte, a la necesidad argumentativa que guarda relación con la demostración de las hipótesis conceptuales; sin embargo, es un recurso narrativo que da forma al texto, ya que lo nutre de la apertura transdisciplinaria, para sacarlo de los límites estrechos del canon del texto científico social. Es así como la intertextualidad presente se percibe en múltiples niveles: una intertextualidad respecto del texto científico sociológico y antropológico, con un recurso permanente a la cita, incluso de textos etnohistóricos como radicalización de la intertextualidad. Aquí no solamente la autora se nutre de la lectura socio-antropológica, sino también de las fuentes del texto pretérito, jugando tanto con la fuente conceptual como también con la fuente de la fuente conceptual. Así se lee:

"venida la noche el Inca señaló, salieron los indios apercibidos de sus armas con grandes fierros y amenazas de vengar las injurias pasadas con degollar los españoles" (Comentarios reales del Inca Garcilaso de la Vega) (Madres y huachos 78). O en una intertextualidad desde el texto literario, planteada como cita directa: “Doña Isabel quería/ suyo y lo mismo la parda, y el Bernardo entre las dos/ como un junquillo temblaba (Gabriela Mistral, Poema de Chile), o respecto del texto literario popular: ...crece el hombre malamente/ arrastrando su cadena / por eso no causa pena ver morir a un inocente (canción de angelito)" (Madres y huachos 92).

Con esto, Montecino le proporciona un rasgo definitorio a la identidad textual, ya que se expresa no solamente por medio de la vinculación de argumentos ajenos, sino de sensibilidades propias en la combinación de la cita ajena y la metáfora propia, donde el argumento toma realmente vida.

Una intertextualidad desde el vocabulario de género donde es posible encontrar permanentemente el recurso a palabras como hilar, bordar, 
tejer, lo que resulta en una transposición entre la autora empírica y la autora textual, y es un contenido estilístico que rápidamente toma un contenido ideológico, demostrando, o intentando demostrar cómo el género se toma la escritura. Una intertextualidad que es extraída de las etnocategorías del mundo popular chileno e indígena latinoamericano, “¡la Tencha nos decía que Allende no servía!" (Madres y huachos 103), "en su calidad de ñusta (princesa) tiene dominio sobre súbditos y soldados" (74). Con ello, la recuperación del habla pasa a ser un tipo de recurso etnográfico, casi un atisbo de fuente empírica, que remite a lo más directo que el tiempo puede tener en una escucha y cita directa respecto del lenguaje del actor.

Por último, destaquemos en nuestra lectura del texto un recurso permanente de tipo intertextual: el epígrafe, que no posee un carácter complementario sino que representa un recurso textual de primer orden, ya sea por las metáforas que contiene como por las ideas que expresa de manera implícita o explícita. Se trata de un tipo de intertextualidad donde existe la presencia física de un texto dentro de otro. Es el caso de epígrafes de poesía como la de Paz o Mistral a la cual recurre constantemente Montecino; el texto citado orienta la lectura, la determina, tiene un rol prevaricador para el lector que se debe guiar por la insinuación que el epígrafe le entrega. Los contenidos en sí son simples, el modo en que orientan la lectura del texto que preceden es lo complejo. El siguiente extracto, prueba de ello, es la transcripción exacta del poema "Identidad" del poeta mexicano Octavio Paz, "en el patio un pájaro pía/ como el centavo en su alcancía/ Un poco de aire su plumaje/ se desvanece en un viraje. / Tal vez no hay pájaro ni soy/ ese patio en donde estoy" (Montecino 1991, 3).

Este texto, que representa el epígrafe fundamental del libro, es en sí un factor intertextual determinante en la caracterización del lector modelo. Si lo que existe en el libro es la pregunta por la identidad, y el libro está elaborado por una escritora y antropóloga, ninguno de los antecedentes anteriores posibles de encontrar en la contratapa deberán hacernos esperar un sesudo estudio sobre cultura nacional al estilo de la antropología psicológica o un estudio antropológico político. Este epígrafe, sacado de Paz, ya nos induce a un texto mucho más subjetivo y polisémico, en el que lo transdisciplinar fundamentado en la metáfora constituye su pilar. 
Este tipo de epígrafes se repite en el texto, y en una caracterización general, los podríamos clasificar en dos tipos: el primero está compuesto por aquellos que rescatan la dimensión poética del libro invitándonos a una reflexión más intuitiva que analítica, como es el caso de los epígrafes de textos de Gabriela Mistral o de Octavio Paz (como el que acabamos de citar). Un segundo tipo de epígrafe tiene el objetivo de centrar la lectura del texto en la problemática del género, específicamente en el terreno de lo femenino. Es el caso de las citas epigráficas de la obra de Tamara Kamenszain ${ }^{5}$ o los cantos en quiché y castellano con que se inicia el capítulo titulado "La virgen Madre emblema de un destino". Pero quizás el más significativo de estos epígrafes de género es el que dice "A Cristián, por haber nacido": en él no sólo se expresa el vínculo emotivo que la autora evidentemente tiene con su hijo, sino que nos orienta la lectura posterior. Desde allí, desde la primera página del libro, el lector tendrá que partir del hecho que está leyendo la obra de una mujer que escribe,. En otras palabras, es una escritura situada. Por lo tanto, esta intertextualidad determina tanto al autor modelo como al autor empírico. Ello es de tal intensidad en la obra toda de Montecino que la última frase del discurso de agradecimiento por el otorgamiento del Premio Academia Chilena de la Lengua 1992, es nuevamente la misma: "a Cristián, por haber nacido (Montecino 1991, 2)."

Respecto de los paratextos, representados por los títulos y subtítulos, vemos en ellos el recurso permanente a la intertextualidad. Desde el título mismo se utiliza una palabra española y una voz indígena: huacho, con lo cual desde este recurso intertextual se nos hace esperar un texto que deambule por las diferentes formas culturales que componen el sistema étnico social latinoamericano. Los subtítulos, en tanto, van desde la descripción casi técnica: "Mujer e identidad latinoamericana: reversión de los paradigmas eurocéntricos" (Madres y huachos 22), hasta la metáfora abierta, "Virgen madre: emblema de un destino" (61). La variedad de modos de titular y subtitular probablemente tengan que ver con la construcción del libro que la autora reconoce, en tanto éste responde a lo dicho en la elaboración de la obra, ya que son "diversos espacios" (15). Es

5 Tamara Kamenszain (Argentina, 1947) es una poeta y ensayista argentina. Descendiente de inmigrantes judíos rusos y rumanos, estudió filosofía. Sus ensayos sobre poesía argentina y latinoamericana son material de estudio en universidades argentinas y del exterior. Sus libros de poesía fueron total o parcialmente traducidos a diversas lenguas y es considerada una de las voces que influyeron sobre las nuevas generaciones de poetas. 
decir, conferencias clases, ponencias charlas, artículos científicos, textos de difusión y comentarios etc. Por ello, aunque suponemos que existió un retocado de los textos para la conformación del libro, ellos de todas formas responden a la lógica de textualidades un tanto disímiles, respondiendo los títulos, tal como vimos, a una intención de orientar pragmáticamente la lectura hacia un argumento claro y preciso, y en otros casos Montecino quiere llevar al lector a una perspectiva más amplia en su lectura donde el tema es más vago por tanto el texto es leído de manera más polisémica.

\section{6. ¿Quién escribe y para quién?}

Para nosotros, es evidente el tipo de autor modelo (Eco, 1981) frente al cual nos encontramos, él (ella) es un ensayista enciclopédico (a), que pasa raudamente desde la teoría literaria a la teoría sociológica, en vuelos rasantes donde historia, antropología, sociología y teoría del género aportan poderosamente. Sin embargo, queda la pregunta fundamental respecto de qué es lo propio de este autor modelo. Es una feminista furibunda que arremete con todas las herramientas de su inteligencia y de su cultura, pero también es una delicada ensayista literaria con un vocabulario exquisito que quiere aportar no sólo desde la reflexión del género sino desde las interrogantes más amplias respecto de nuestra identidad sincrética y mestiza: una escribidora sudaka.

En resumen, más allá del marcado tinte ideológico feminista de la escritora, la autora modelo presente es la de una especialista en estudios culturales, cuya identidad muy particular se define por su preocupación por el estilo, en el sentido de la búsqueda empedernida de la belleza en la expresión. No es gratuito, por cierto, el premio Academia Chilena de la Lengua que este libro obtuvo. Existe en el texto una cierta elegancia profunda que supera a la metalengua misma, casi como si la belleza del estilo nos hiciese distraernos de los argumentos planteados.

La identidad de la autora modelo es también la de una literata muy culta, que desde el pluralismo inter y transdisciplinario de la ciencia antropológica lo cual le permite ir y venir desde y hacia otras disciplinas; elabora un texto de reconocida belleza, es por ello más que un texto de teoría, una primera muestra de un tipo textual emergente, el ensayo antropológico poético literario sudamericano, donde no sólo importa decir cosas cuerdas, sino también decirlas bien, siendo coherentes con 
una suerte de barroquismo, bien entendido, es decir un cuidado por la forma, que no la frena pero la pule.

En cuanto al lector modelo, él supera a la comunidad antropológica, aunque evidentemente no responde a la búsqueda de una lectura masiva. Este lector debe superar el plano técnico para llegar a la búsqueda interdisciplinaria; no es el practicante de una disciplina sino un lector instruido, un raro espécimen, que no obstante parece abundar en Chile si lo consideramos en función de la recepción y de la reedición de la obra.

Nuevamente nos vemos frente a un lector cuyo universo es el de la intelectualidad de clase media chilena, la que se interroga por el género y por la identidad cultural, la que lee a Pedro Morandé, a Carlos Cousiño, a Julieta Kirkwood, a Gabriel Salazar y a Jorge Guzmán. Un tipo de intelectual pluralista con intereses amplios y con un bagaje de lecturas que le permiten llenar de significados los significantes que el texto utiliza, pero también es un lector con un habitus de clase (Bourdieu, 1995), el cual necesita de la formación universitaria para comprender, y del desconcierto propio de la pequeña burguesía de la década de los ochenta. Alguien que además esté dispuesto a dejarse seducir por el argumento, alguien que no busca sólo evidencia empírica sacada del terreno, sino que esté dispuesto a seguir el hilvanado del texto, a recorrer los trazos y la textura; alguien que es capaz de hacer la travesía, solamente escoltado por la seducción del estilo. Un lector que se hace preguntas sobre sí mismo y sobre su medio, y que para responderlas no tiene miedo a realizar los cruces ni a dejar que otros los hagan.

Una demostración de ello es el uso del concepto de barroco latinoamericano ya demostrado aquí, creado originalmente por autores como Carpentier y De Rokha y re-utilizado por Morandé. La llegada de esta analogía barroca al texto de Montecino consiste en una travesía aquí; va desde la metalengua del real maravilloso pasa con Morandé hacia la sociología y recala en el puerto del texto antropológico literario.

Por todo lo anterior, este tremendo camino da cuenta de un lector capaz de aceptar la aventura. No obstante, nos preguntamos ¿Quién le dijo a Montecino que ello era posible?, ¿Quién la autoriza para sacar categorías de campos y subcampos culturales tan distintos y mezclarlos en su obra de artesanía? La audacia teórica es en este libro, en mucha 
medida, la audacia de la mezcla inaudita, y Montecino supone un lector modelo que la autoriza, un alguien que le da el permiso tolerante y maravillado.

\subsection{Un habitus para dar razón de las esperanzas}

En su materialidad, la escritura misma de este libro de Montecino no difiere del estilo del ensayo histórico social. Tomás Lago podría haber escrito un texto que en su apariencia, aunque no en sus argumentos macroestructurales (Van Dijk, 1989), se asemejase al de Montecino. No obstante, no son sólo los argumentos lo que diferencia a este texto: la libertad se une al plano de la formalidad en la presentación de los argumentos. Se debe escribir bellamente, pero el argumento debe estar bien formulado. Es así el habitus (Bourdieu, 1995) que esta obra genera, obliga a plantear argumentos cuyas bases sean sólidas y que también su estructura lógica resulte verosímil. Esta credibilidad, unida a la estética de la expresión representa la base del habitus cuyos límites están en dos vértices, la argumentación del ensayo sociológico y la creación ensayística literaria. Un ángulo necesita del otro para poder existir.

Toda lectura del texto de Montecino, y de los que en el futuro seguirán su huella al interior de la Antropología Poético Literaria Chilena, deberán atenerse a estos dos primados: el primero es el cuidado en el estilo, que aventure experiencias y experimentos textuales desde la metáfora, el segundo es retórica y semántico en el detallado proceso de fundamentación indiscutiblemente sus afirmaciones. La belleza en la expresión deberá estar unida a la coherencia en el pensamiento. El resto es solo antropología poética ditirámbica.

La generación de ideología, en este caso ideología (forma de retórica y semántica subyacente) de género, resulta en un factor que define; los valores son claros, no dan cabida a la duda, no obstante este ensayo y todos aquellos que caben al interior de nuestra antropología literatosa experimental, no responden necesariamente a esta lógica de clara base axiológica. En definitiva, no es necesario ser feminista, ni teórico del género para adscribirse a este tipo textual. Más bien, la búsqueda estética en el plano del estilo y la coherencia argumentativa son los componentes del núcleo duro que nos proporcionan la gramática mínima de este habitus creativo. 
Respecto del epicentro barroco, creemos que él representa el ángulo de juego o movimiento, que aunque no se mantiene en textos ensayísticos de autores posteriores, representa el epicentro de la perspectiva interdisciplinaria, tanto a nivel del argumento como a nivel de los tipos textuales utilizados. Para Montecino, América Latina es barroca; desde las tesis del Proyecto Ecuménico del Barroco de Pedro Morandé (1984), ello no sólo se sustenta en una reflexión teórico-sociológica, sino que posee reminiscencias implícitas en el barroquismo literario y metalingüístico de autores como Alejo Carpentier o José Lezama Lima, y en el barroco colonial latinoamericano, frecuentemente mencionado por la autora. Por ello, el barroco no es solo un período de la cultura europea y latinoamericana; es un tipo ideal teórico sociológico, una analogía estética y un modo de encarar la escritura del texto.

El carácter recargado de la estética barroca atraviesa la comprensión de la identidad chilena y latinoamericana, pero supera el plano del argumento. Por este motivo, el habitus es barroco en su originalidad, dado aunque no se usen las categorías de Morandé, ni se mencione el barroco como corriente estética, se sigue elaborando desde 1992 (año en que se publica el libro) un tipo de ensayo recargado en su estilo, preocupado tanto de la coherencia analítica del argumento como de la forma estética de lo dicho, en el que la metáfora no sólo es una licencia, sino una exigencia del estilo de creación que Montecino inaugura.

Este habitus de creación tiene como punto de articulación el mismo eje descubierto en su metalengua, el barroco. Se trata de un permiso para la forma recargada que echa mano del argumento racional traído desde diferentes disciplinas. Pero también se provee de la cita al poema, del poema como epígrafe que define sentido, y sobre todo de la metáfora. Parece que la autora más que convencer racionalmente, lo que desea es seducir con la forma expresiva. Esa combinación y elocución lograda por la metáfora, metáfora utensilio, que no es grandilocuente, sino de "gran elocuencia".

\section{Conclusiones}

Si el padre es ausencia, ¿cómo se integra la cosmovisión y el sistema étnico social? Desde el pensamiento de Sonia Montecino, aunque sin hacerla solidaria de estas reflexiones, podemos continuar el camino reflexivo, sin temor y sin pausa; desde el pensamiento lacaniano, asumir 
el barroquismo esencial como fundamento del diagnóstico. La necesidad del hombre como marido, padre, presencia, con un gran etcétera, resulta en una apariencia, necesaria como protector, principalmente respecto del acoso sexual, pero en lo profundo el sistema de representación y de sentido manipula desde "el hombre".

Es el hombre apariencia, sobreactuado y arquetípico, macho con los pies de barro y los ojos miopes, en apariencia, lo masculino es la gran máscara latinoamericana, detrás de toda gran mujer hay un hombre que más que persona es un espectro, el género masculino no se ha recentrado desde la irrupción de la mujer en el sistema productivo y lastimeramente se debate entre la agresión y el femicidio, y así ocurre la inseguridad incluso sexual.

No hay aquí envidia de pene, hay utilización de la imagen para darle un sentido oblicuo, una cobertura detrás de la cual se trenza y se borda la trama de lo femenino, como epicentro del efectivo funcionamiento del aparato simbólico (como fundamento lacaniano de lo real): mujer madre de familia, mujer sostenedora, mujer jefa de familia, mujer madre que manipula y determina, mujer amante que se apodera del deseo y de la voluntad del hombre, mujer protectora de la inseguridad frente a las hostilidades del contexto, mujer hombro, mujer pañuelo, mujer discreta, mujer apologista, mujer bastón, mujer huella psíquica: ella no existe sin el hombre, como Lacan afirmó, pero ella lleva sobre sus hombros todos los significados, muta con ellos, se adapta, se solapa, se impone, siempre define, aunque pague el costo de pasar a la segunda fila del coro griego como replicante: es simultáneamente trueno y susurro.

Nunca podemos olvidar que la identidad barroca sudamericana es también tridentina, se forja no solo en la estética de la exacerbación de la forma, sino también en la teología de la contrarreforma. Así, si teológicamente se enarbola un Dios varón, castigador y padre, se refuerza el culto mariano. En este sentido, como medio de difundir aquel discurso de manera eficiente, como Pablo en Atenas frente a la estatua del Dios desconocido, los evangelizadores utilizaron los cultos femeninos y los sincretizaron con el culto mariano y de las Santas. Así, lo mariano es una forma de colonialismo cultural barroco y tridentino, pero también es una manera de rescatar lo materno y, por tanto, lo femenino vernáculo y esencial. 
No es casualidad que catolicismo e Islam rescaten la figura de la Virgen María, y en el caso del barroquismo tridentino de Europa y Latinoamérica, ocurra que las advocaciones de la virgen y las santas pueblan el imaginario y lo simbólico, constituyendo una materia prima fundamental de lo real: con un semi-politeísmo, muchas veces de corte panteísta, que puebla el imaginario y la ritualidad propia de las formas culturales mestizas latinoamericanas.

La madre es generadora de protección pero también de culpa. Psicoanalíticamente, el padre puede y debe ser asesinado en un momento del devenir dela cadena significante, trasladada alabiografía; sin embargo, la madre no puede ser asesinada. Los latinoamericanos nunca, como los ríos encausados, podemos "salimos de madre". Si hemos dicho que la mujer tiende a defender valores que la perjudican, es justamente porque en la supremacía de lo femenino sustentada, antes de la secularización por ser "santas y vírgenes", se enarbolan valores falocéntricos, pero se pone a la virgen o la Santa en el centro del rito. En Santuarios desde Maipú en Chile, hasta el de Guadalupe en México, pasando por los carnavales y fiestas del área andina y amazónica (al comunismo del incanato de José Carlos Mariátegui le faltó este componente femenino para comprender el ejercicio del poder en ese mito, eficiente y genuino, de socialismo no europeo), pareciera que Cristo varón es un accidente en el rito religioso popular latinoamericano, y con justicia Leonardo Boff ha hablado del "rostro materno de Dios". La refundación de lo latinoamericano desde la conquista, y Chile es un ejemplo más, requirió de los valores del imperio y de la Ecúmene Universal Católica Romana; pero en los intersticios, en los pliegues, lo femenino conservó, desde la cercanía y la sutileza, la dimensión femenina.

Esto va más allá de la axiología, es más profundo que los valores, es en sí la supremacía del significante. Si la Virgen nominalmente es subalterna en la teología, la santa es un aspecto de la catolicidad. Con el correr del tiempo, donde los cultos religiosos pasaron de ser considerados por parte de la elite católica latinoamericana como paganismo y borrachera, son hoy "semillas del verbo" según la teología católica posterior al Concilio Vaticano II. Lo femenino, bajo la forma del significante dual virgen y santa, se constituyó en el epicentro de la cultura. Que lo femenino defienda valores machistas como la agresividad, no significa que el falocentrismo eurocéntrico determine la cultura. En el juego de los entresijos, en el 
avatar de los significados múltiples, y en lenguas romances donde el rito es acompañado por unas palabras eficientemente polisémicas, el control femenino, su elevación a algo sagrado, actúa y es eficiente: la madre es sagrada, la hermana virginal, la casta esposa. Lo femenino integra a la estructura y proporciona sentido desde el revés, desde el velo, desde la apariencia y desde el significado solapado.

En su socialización la mujer latinoamericana es naturalizada en el manejo de esos códigos y esos procedimientos. Dejar que lo masculino enarbole su plumaje, pero operar desde el acápite, desde lo no evidente. La virgen o la santa, muñeca vestida con ropajes lujosos, donde es la miseria muchas veces lo que impera, es un modo de que lo mariano sea el falo totémico, sostén simbólico y figura de la ley. La virgen blanca y europea adquiere una morenidad, una sudamericanidad, sobre la base de un poder simbólico y por tanto de una eficiencia simbólica. La virgen y la santa son cercanas, es la madre tolerante y comprensiva, objeto y sujeto de pudor. En Latinoamérica, la cultura opera sostenida por ese sometimiento a la feminidad. Es lo femenino como un amplio significante pero también es un falo mestizo erigido en el centro del rito, desde la más radical feminidad redefinida. Lo femenino bajo la forma de la madre, virgen, barroca y sudamericana es signo de poder y también de subversión. Es la virgen de los ladrones en Chile, o la virgen de los sicarios en Colombia, como la virgen ícono del movimiento de César Chaves en Norteamérica.

Aún no aquilatamos hasta donde este absoluto femenino, este arquetipo del eterno femenino oculta las posibilidades y las formas manifiestas y actuantes de la insubordinación y del desacato. Se puede ser el falo totémico como madre de familia, como imagen de la virgen o advocación de la virgen santa. Y la fuerza simbólica y política de esa imagen esconde sin duda el temor radical al incesto y la seducción que respecto de él, universal y solapadamente, sentimos. 


\section{Bibliografía}

Alvarado, Maite. Paratexto. Argentina: Ediciones Universidad de Buenos Aires, 1994.

Bourdieu, Pierre. Cosas Dichas. Barcelona: Gedisa, 1995.

Butler, Judith. Cuerpos que importan. Buenos Aires: Paidós, 2002. . Lenguaje, poder, identidad. Madrid: Síntesis, 2004. . Deshacer el género. Buenos Aires: Paidós, 2006. . El género en disputa. Barcelona: Paidós, 2001.

Eco, Umberto. Lector in fabula. La cooperación interpretativa en el texto narrativo. Barcelona: Editorial Lumen, 1981.

Guzmán, Jorge. Diferencia latinoamericana. Santiago: Ediciones del Estudios Humanísticos de la Universidad de Chile, 1984.

Guzmán, Jorge. Contra el secreto profesional. Santiago: Editorial Universitaria, 1991.

Mignolo, Walter. Teoría del texto e interpretación de textos. México: Ediciones de la Universidad Autónoma de México, 1986.

Montecino, Sonia. Madres y huachos. Alegorías del mestizaje chileno. Santiago: Cuarto Propio-Cedem, 1991.

- Discurso entrega del premio Academia Chilena de la Lengua. Santiago: s.e., 1992.

Morandé, Pedro. Cultura y modernización en América Latina. Cuadernos del Instituto de Sociología UC. Santiago de Chile: Ediciones Universidad Católica, 1984.

Roudinesco, Élisabeth. Jacques Lacan. Esquisse d'une vie, histoire d'un système de pensé. Paris: Fayard, 1993.

Van Dijk, Teun. La ciencia del texto. Un enfoque Interdisciplinario. Buenos Aires: Paidós, 1989. 